\title{
Converting threats from COVID-19 in long term care into opportunities for improvement
}

\author{
Leona Konieczny* \\ Central Connecticut State University, United States
}

Received: December 5, 2021

DOI: $10.5430 / \mathrm{cns} . v 9 \mathrm{n} 2 \mathrm{p} 36$
Accepted: January 3, $2022 \quad$ Online Published: January 6, 2022

URL: https://doi.org/10.5430/cns.v9n2p36

\begin{abstract}
The effects of the COVID-19 pandemic on long term care (LTC) have been published in the literature and experienced by residents, their support persons and nursing staff. The morbidity and mortality, as well as the threats of isolation and psychosocial distress continue. Both LTC residents and staff experience physiological and psychological impacts. Nurses can use the current threats produced by the pandemic to advocate for alternate models of care and reduced isolation for residents. The pandemic is an opportunity for nursing advocacy in LTC for shared governance and empowerment, involvement in policy development, and oversight in policy implementation. Nurses are presented with the opportunities for advocacy related to resources and reshaping the paradigm of residential care for older adults.
\end{abstract}

Key Words: Advocacy, COVID-19, Long-term care, Nurse

\section{INTRODUCTION}

The sustained effects of the COVID-19 pandemic on long term care (LTC) have been published in the literature, covered in the media, and experienced by residents, their support persons and nursing staff. The fatality rate, as compared to the infection rate, is disproportionally higher among residents in long term care. ${ }^{[1]}$ The Centers for Medicare \& Medicare site, updated on 2nd December 2021, report 730,867 confirmed COVID-19 cases among residents with 140,563 resident deaths (19.2\% mortality). There are 682,282 confirmed staff cases with 2,157 staff deaths $\left(0.003 \%\right.$ mortality). ${ }^{[2]}$ The COVID-19 pandemic threats and harms have been experienced globally. ${ }^{[3-5]}$ This article focuses on LTC translating threats into opportunities in LTC in the United States of America (USA).

\section{THREATS FROM COVID-19}

In addition to the mortality in LTC, the clinical presentation and containment strategies produce deleterious effects. The most common presentations include fever, non-productive cough, and dyspnea. ${ }^{[6]}$ However, among LTC residents, diarrhea, fall, delirium, and hypothermia can be initial symptoms. ${ }^{[7]}$ Other non-specific or vague symptoms such as decreased appetite, decreased energy, and confusion may precede more typical symptoms. ${ }^{[8]}$ Co-morbidities such as diabetes, chronic respiratory disease, cerebrovascular disease, immunosuppression, dementia is recognized as risks for increased morbidity and mortality from COVID- 19. The frail residents with multiple comorbidities had physiological deterioration from the virus and little emotional support due to no visitor restrictions aimed at containing the virus.

*Correspondence: Leona Konieczny; Email: lakonieczny@ gmail.com; Address: Central Connecticut State University, United States. 
A study by Mo and Shi report loneliness, fear, and anxiety are common psychological effects among the residents due to the illness and isolation. ${ }^{[9]}$ Mo and Shi report anxiety or uncertainty, helplessness, and work overload are common psychological effects among LTC staff. ${ }^{[9]}$ A qualitative study, by White, et al., among nursing staff in LTC describes fear of infections for themselves or their families, empathy for the residents, and burnout due to heavy workloads, personal protective equipment shortages, and high levels of stress. ${ }^{[10]}$ Persons with dementia account for a large portion of LTC residents. These residents may find it difficult to adhere to protocols such as social distancing or the wearing of masks. There may be increased walking resulting from boredom or unused energy because of reduced recreation events resulting from COVID-19 restrictions. The increased ambulation may increase the risk for elopement. The frequent walking puts a strain on the residents and the nursing staff. The environments in LTC may have poor ventilation, insufficient visual cues, and shared bedrooms and bathrooms. The factors may have contributed to the rapid spread of the virus in LTC. ${ }^{[1]}$

\section{OPPORTUNITIES FOR IMPROVEMENT}

The pandemic is a call to action for nurses, providers, policy makers, and communities to improve quality of life and standard workflow in LTC. A study, by Haugan, et al., in 2020 demonstrates the use of the Older People's Quality of Life survey in long-term care. The Older People's Quality of Life (OPQoL) brief survey contains thirteen items concentrating on enjoying life, staying involved, looking forward to things, feeling safe, having help available, and enjoying leisure/social activities or hobbies. ${ }^{[12]}$ Their findings show 49.7\% report high Quality of Life (QoL). Modest QoL reported at $42.5 \%$ and $6.1 \%$ were reported as low. ${ }^{[12]}$ There is improvement needed when half of the residents perceive quality of life as less than high.

The Dementia Village from the Netherlands is a recognized, publicly funded model which varies greatly from most LTC in the USA. The model is based on seven pillars which are favorable surroundings like a home, life's pleasure and meaning, health, lifestyle, employees and volunteers with a shared mission, resident centered organization, and emancipation and inclusion. ${ }^{[11]}$ There are approximately twelve residents per building compared to some LTC facilities which can house hundreds in institutional style buildings. Pedro, et al., have conducted a literature review on dementia care villages as an alternative care model ${ }^{[13]}$ and found improved functioning, decreased use of antipsychotic medications (from $50 \%$ to $12 \%$ ), and increased job satisfaction for the staff associated with dementia care villages. ${ }^{[13]}$

Various stakeholders and policy makers need proactive inPublished by Sciedu Press volvement for a change in housing LTC residents. Funding has increased to keep older adults in their homes longer which has increased quality of life and decreased costs as compared to traditional LTC. But there will continue be older adults due to lack of support person(s) or physical resources who will need residential care. Changes and the accompanying funding are not expected quickly. In the current environment, nurses are called to advocate for adequate personal protective equipment, standard work practices to keep residents and staff safe, and engineering controls to minimize the threats of infection. ${ }^{[14]}$ Many LTC facilities usually have two residents per room and often share a bathroom with two rooms. Private rooms with ensuite bathrooms are recommended to break the chain of infection. A private bathroom is an engineering measure to reduce transmission of infection in LTC. ${ }^{[14,15]}$

Currently in the USA, $86.7 \%$ of residents are COVID-19 vaccinated and $75.1 \%$ of staff are vaccinated. ${ }^{[2]}$ The nursing staff are frequently vectors for the spread of infection. The need to educate the staff and dispel myths about COVID-19 vaccination prevails. Certified Nursing Assistants (CNAs) are the majority of the direct care givers. CNAs and nurses may work in more than one facility which is a risk factor for viral spread. Konetzka describes the strongest predictor of COVID-19 cases and deaths in LTC is the prevalence in the county. ${ }^{[16]}$ Konetzka also describes no relationship between nursing home quality as defined by the Nursing Home Compare five-star rating and COVID-19 outcomes. ${ }^{[16]}$ The pandemic illustrates LTC is unsafe in its current form. Nursing has an opportunity to participate into reshaping care of older adults from an institutional model to a person-centered, age friendly, ability and health focused paradigm. ${ }^{[17]}$ There is an opportunity to change staffing models in LTC. The federal government's requirement for a professional registered nurse is eight consecutive hours seven days a week per facility. ${ }^{[18]}$ The licensed nurses, usually LPN or LVN, staff around the clock care. The role APRN in LTC is as a mid-level provider. Because of time limitations or standard work practices, this role is not often utilized as a resource for nursing staff. There is a need to elevate the nursing practice in LTC. The Clinical Nurse Specialist (CNS) has the knowledge and talent to provide expertise, support nursing staff, and encourage best evidence-based practices to achieve quality outcomes. ${ }^{[19]}$ Administrators in LTC need to reprioritize financial resources and nursing workflow to utilize the CNS to positively affect LTC personnel and residents.

\section{ADVOCACY}

Nurses need to advocate on a broader arena both within and beyond the walls of LTC. Nurses contribute to advocacy by 
serving on boards and becoming active in policy development and administration of facilities and programs. Within LTC, nurses can continue to promote vaccination and adequate personal protective equipment (PPE) for staff. The American Nurses Association (ANA) issued a statement on the 18th of March 2021 to the Senate Health, Education, Labor, and Pension Committee hearing advocating vaccination for nurses and all other health care workers as well as equity in vaccine distribution. ${ }^{[20]}$ State nursing organizations are advocating for COVID-19 vaccination to reduce the risk of infection present in nursing care. ${ }^{[21-24]}$ Nurses working in LTC can participate in shared governance. Shared governance is a supportive structure which focuses on best practices and outcomes with shared vision, accountability, and success. ${ }^{[25]}$ Christ writes nurse participation in care decisions has helped COVID-19 responses and empowered nurses. ${ }^{[26]}$ Nurses, in LTC, have the opportunity to make improvements by engaging in shared governance. In a qualitative study, McMillan, et al., report nurses found the policies which separate people from families to be incongruent with nursing values and ethics. ${ }^{[27]}$ Nurses are integral to an interdisciplinary team with social workers, recreation therapists, community liaisons, and administrators to connect residents with family or support persons using technology or

Table 1. Threats and opportunities

\begin{tabular}{|c|c|}
\hline Threat & Opportunity for Nursing \\
\hline \multirow{2}{*}{ COVID-19 infection for residents, nurses, families } & Empowerment to advocate for PPE \\
\hline & Education related to COVID-19 vaccination \\
\hline Social Isolation for residents related to containment strategy & $\begin{array}{l}\text { Shared governance to collaborate with social workers, recreation } \\
\text { therapists, community liaisons, and administrators }\end{array}$ \\
\hline LTC environment with shared rooms and shared bathrooms & Shared governance for structural change in LTC \\
\hline \multirow{2}{*}{ Poor outcomes for residents } & Shared governance for nurses as SME \\
\hline & Shared governance for alternate staffing to include CNS \\
\hline Increased workload for nursing staff & Shared governance for change in staffing model \\
\hline Institutional, medical model in LTC & $\begin{array}{l}\text { Advocacy for policy change for alternate, person-centered models } \\
\text { for residential care for older adults }\end{array}$ \\
\hline
\end{tabular}

\section{Conclusions}

The Covid-19 pandemic is threatening and damaging for residents in LTC with actual infections, restriction of usual activities such as dining or recreation, and isolation from direct contact with family or support persons. Support persons by developing and implementing policies which meet both biomedical and humanistic needs.

Advocacy may be applied within a broader context for nurses to embrace alternate staffing models beyond the mandated federal or state regulations. Nurses' advocacy can be leveraged to include input into policy development at the local, state, and/or federal levels. Anders writes the voice of nursing is missing in health care reform and in developing health care regulations. ${ }^{[28]}$ Clinical nurses who provide direct patient care are the subject matter experts (SME). Because nurses who work in LTC may provide care to the same residents for years, Anders notes that nurses are uniquely positioned as SMEs because the public has voiced trust in the profession of nursing. ${ }^{[28]}$ Nurses may provide testimony as politicians are stakeholders in the welfare of the older adult in the community. Nurses may approach advocacy as an individual SME or by participation in professional nursing organization(s). Waddell, et al., issue a call for nurses and nursing organization to be "intentional, principled, and responsive" in meeting nursing's ethical mandate to society. ${ }^{\text {[29] }}$ Nurses may use their advocacy to improve conditions in the current LTC model or create a new model such as smaller group homes or villages which promote person-centered care. Please see Table 1 for summary of threats and opportunities. 
be utilized to improve quality for older adults in LTC and their nursing staff. Nurses have the intellectual capital and the ability to collaborate with other stakeholders to create opportunities for enhanced care for older adults. Advocacy may take the form of shared governance and empowerment and/or

\section{REFERENCES}

[1] Ghmelin G, Munoz-Price LS. Coronavirus disease 2019 (COVID19) in long term care facilities: a review of epidemiology, clinical presentations, and containment interventions. Infection Control \& Hospital Epidemiology. 2020; 1-6. PMid: 33100245. https: //doi.org/10.1017/ice.2020.1292

[2] COVID-19 Nursing Home Data. Centers for Medicare \& Medicaid Services. [Accessed Dec. 5, 2021]. Available from: https: //data.cms.gov/covid-19/covid-19-nursing-home-data

[3] Cesari M, Proiettei M. Geriatric Medicine in Italy in the time of COVID-19. Journal of Nutrition Health and Aging. 2020; 24: 459460. PMid: 32346679. https://doi.org/10.1007/s12603-0 20-1354-z

[4] Rolland Y, Benetos A, Villars H, et al. A COVID-19 support platform for long term care facilities. Journal of Nutrition Health and Aging. 2020; 24: 461-462. PMid: 32346680. https://doi .org/10.100 $7 / \mathrm{s} 12603-020-1364-\mathrm{x}$

[5] Huedorf H, Muller M, Schmehl C, et al. COVID-19 in long term care facilities in Frankfurt am Main Germany: incidence, case reports, and lessons learned. GMS Hygiene Infection Control. 2020; 15: 1-13. Available from: https://www.egms.de/static/en/journals /dgkh/2020-15/dgkh000361.shtml

[6] Naderpour Z, Saeedi M. A primer on COVID-19 for clinicians: clinical manifestation and natural course. Advanced Journal of Emergency Medicine. 2020; 4: 1-8. Available from: https://fem.tums.ac. $\mathrm{ir} /$ index.php/fem/article/view/418/290

[7] Blain H, Rolland Y, Benetos A, et al. Atypical clinical presentation of COVID-19 in residents of a long term care facility. European Geriatric Medicine. 2020; 11: 1085-1088. PMid: 33025500. https://doi.org/10.1007/s41999-020-00352-9

[8] Kim JJ, Coffey KC, Morgan DJ, et al. Lessons learned - outbreaks of COVID-19 in nursing homes. American Journal of Infection Control. 2020; 1279-1280. PMid: 32739235. https://doi.org/10.1016/ j.ajic.2020.07.028

[9] Mo S, Shi J. The Psychological Consequences of the COVID-19 on residents and staff in nursing homes. Work, Aging, and Retirement. 2020; 6: 254-259. PMid: 34192005. https://doi.org/10.1093/ workar/waaa021

[10] White EM, Whetle TF, Reddy A, et al. Front-line nursing home staff experiences during the COVID-19 epidemic. Journal of the American Medical Directors Association. 2021; 22: 199-203. PMid: 33321076. https://doi.org/10.1016/j.jamda.2020.11.022

[11] Olson NL, Albensi BC. Dementia-friendly "design": impact on COVID-19 death rates in long-term care facilities around the world. Journal of Alzheimer's Disease. 2021; 81: 427-450. PMid: 33814449. https://doi.org/10.3233/JAD-210017

[12] Haugan G, Drageset J, Andre B, et al. Assessing quality of life in older adults: psychometric properties of the OPQoL-brief questionnaire in a nursing home population. Health and Quality of Life policy development and oversight. Nurses are uniquely positioned with the knowledge, attitude, and skills to create improved conditions for the residents and themselves.

\section{CONFlicts OF InTEREST Disclosure}

The authors declare they have no conflicts of interest.
Outcomes. 2020; 18(1). PMid: 31898546. https://doi.org/10 $.1186 / \mathrm{s} 12955-019-1245-3$

[13] Pedro C, Duarte M, Jorge B, et al. Dementia villages: rethinking dementia care. International Psychogeriatrics. 2020; 32: 158 https://doi.org/10.1017/S1041610220002926

[14] Benbow W. Engineering controls for long term care facilities to prevent and manage infectious diseases such as COVID-19. Canadian Nursing Home. 2020; 31: 4-13.

[15] Ayukekbong J. Infection prevention and control in long-term care: Lessons learned from COVID-19 outbreaks and future perspectives. Canadian Nursing Home. 2021; 36: 16-19.

[16] Konetzka RT. Improving the Fate of Nursing Homes During the COVID-19 Pandemic: The Need for Policy. American Journal of Public Health. 2021; 111: 632-634. PMid: 33507802. https: //doi.org/10.2105/AJPH.2020.306107

[17] Inzitari M, Risco E, Cesari M, et al. Nursing homes and long-term care after COVID-19: a new era? Journal of Nutrition, Health \& Aging. 2020; 24: 1042-1046. PMid: 33244558. https://doi.or $\mathrm{g} / 10.1007 / \mathrm{s} 12603-020-1447-8$

[18] HHS OIG Data Brief. U. S. Department of Health and Human Services, Office of Inspector General. 2020; 1-38. Available from: http s://oig.hhs.gov/oei/reports/OEI-04-18-00450.pdf

[19] What is a CNS? National Association of Clinical Nurse Specialists. [Accessed Dec. 5, 2021]. Available from: https://nacns.org/ab out-us/what-is-a-cns/

[20] Record from ANA to the Senate Health, Education, Labor, and Pensions Committee. ANA Enterprise. [Accessed Dec. 27, 2021] Available from: https://www.nursingworld.org/practic e-policy/work-environment/health-safety/disaster-p reparedness/coronavirus/what-you-need-to-know/legi slative-and-regulatory-advocacy/march-18-2021-ana -statement-for-the-record/

[21] ANA supports COVID-19 vaccination for nurses and all health care professionals. Vermont Nurse Connection. 2021; 24(1).

[22] Casper C. Colorado Nurses Support COVID-19 Vaccination, Colorado Nurse. 2021; 9.

[23] Morgan E. COVID-19 vaccinations: knowledge vs. myth to get back to a new normal. Tennessee Nurse. 2021; 20-21.

[24] ONA Statement on COVID-19 vaccination. Oklahoma Nurse. 2021; 6. https://doi.org/10.12968/indn.2021.9.6

[25] Brennan D, Wendt L. Increasing quality and patient outcomes with staff engagement and shared governance. Online Journal of Issues in Nursing. 2021; 26. https : //doi.org/10.3912/0JIN.Vol26No $02 \mathrm{PPT} 23$

[26] Christ G. Adding nurses' voices to pandemic decision making. Modern Healthcare. 2020; 50.

[27] McMillan K., Wright DK, McPherson CJ, et al. Visitor restrictions, palliative care, and epistemic agency: a qualitative study of nurses' relational practice during the coronavirus pandemic. Global 
Qualitative Nursing Research. 2021; 8: 1-12. PMid: 34761076 https://doi.org/10.1177/23333936211051702

[28] Anders RL. Engaging nurses in health policy in the era of COVID-19. Nursing Forum. 2020; 89-94. PMid: 33022755. https ://doi .or $\mathrm{g} / 10.1111 /$ nuf .12514
[29] Waddell A, Sundean LJ, Pulcini J. Business over mission: whose voices are being heard? Policy, Politics \& Nursing Practice. 2020; 22: 3-5. PMid: 33423611. https://doi.org/10.1177/152715 4420983969 